\title{
In vitro and in vivo inhibition of rabies virus replication by RNA interference
}

\author{
Ekaterina A. Durymanova Ono ${ }^{1,2}$, Keila Iamamoto ${ }^{1,2}$, Juliana G. Castilho ${ }^{2}$, \\ Pedro Carnieli Jr. ${ }^{2}$, Rafael de Novaes Oliveira ${ }^{2}$, Samira M. Achkar ${ }^{2}$, Maria L. Carrieri ${ }^{2}$, \\ Ivanete Kotait $^{2}$, Paulo E. Brandão ${ }^{1}$ \\ ${ }^{1}$ Faculdade de Medicina Veterinária, Universidade de São Paulo, São Paulo, SP, Brazil. \\ ${ }^{2}$ Instituto Pasteur, São Paulo, SP, Brazil.
}

Submitted: April 07, 2011; Approved: June 05, 2012.

\begin{abstract}
Rabies is a zoonotic disease that affects all mammals and leads to more than 55,000 human deaths every year, caused by rabies virus (RABV) (Mononegavirales: Rhabdoviridae: Lyssavirus). Currently, human rabies treatment is based on the Milwaukee Protocol which consists on the induction of coma and massive antiviral therapy. The aim of this study was to assess the decrease in the titer of rabies virus both in vitro and in vivo using short-interfering RNAs. To this end, three siRNAs were used with antisense strands complementary to rabies virus nucleoprotein $(\mathrm{N})$ mRNA. BHK-21 cells monolayers were infected with 1000 to $0.1 \mathrm{TCID}_{50}$ of PV and after 2 hours the cells were transfected with each of tree RNAs in separate using Lipofectamine-2000. All three siRNAs reduced the titer of PV strain in a least $0.72 \operatorname{logTCID} \mathrm{D}_{50} / \mathrm{mL}$ and no cytotoxic effect was observed in the monolayers treated with Lipofectamine-2000. Swiss albino mice infected with 10.000 to $1 \mathrm{LD}$ of PV strain by the intracerebral route were also transfected after two hours of infection with a pool 3 siRNAs with Lipofectamine- 2000 by the intracerebral route, resulting in a survival rate of $30 \%$ in mice inoculated with $100 \mathrm{LD} 50$, while the same dose led to $100 \%$ mortality in untreated animals. Lipofectamine-2000 showed no toxic effect in control mice. These results suggest that intracerebral administration of siRNAs might be an effective antiviral strategy for rabies.
\end{abstract}

Key words: rabies, RNA interference, siRNAs, antiviral, treatment.

\section{Introduction}

Rabies is an acute infectious zoonosis of the central nervous system of mammals caused by Rabies virus (RABV) (Mononegavirales: Rhabdoviridae: Lyssavirus) normally transmitted by the saliva of an infected host, with a fatal outcome (Rupprecht et al., 2002; Acha 2003). The disease has a dramatic clinical course, going from fever, muscle pain and headaches to altered behavior, autonomic dysfunctions and paralysis culminating with death (Butron et al., 2005). RABV has $75 \mathrm{~nm}$ in diameter and $150-300 \mathrm{~nm}$ in length, with a spiked envelope formed by the $G$ glycoprotein and $\mathrm{M}$ matrix protein, with a ribonucleocapsid formed by the L RNA-dependent RNA-polymerase, $\mathrm{P}$ phosphoprotein and $\mathrm{N}$ nuceloprotein containing the $12 \mathrm{~kb}$ negative-sense single-stranded non-segmented RNA (Kaplan 1996; Tordo and Poch, 1998; Wunner 1991). The search for antivirals against rabies is one of the frontiers in the field but, despite a protocol (the Milwaukee Protocol) based on ketamin, ribavirin, midazolam and amantadin was successful after the treatment of a human patient (Willoughby et al., 2005), it was shown as not reproducible. RNA interference is an alternative as antiviral technology against RABV already shown as effective in vitro in cell cultures (Brandão et al., 2007; Israsena et al., 2009), but no reports on its in vivo use exist hitherto.

This article reports on the in vitro and in vivo posttranscriptional gene silencing of RABV using three shortinterfering RNAs (siRNAs) targeted to the nucleoprotein mRNA using a cationic lipoid as a transfection agent. 


\section{Materials and Methods}

\section{Reference RABV strain}

In vivo and in vitro assays were carried out with the PV strain of RABV grown in BHK-21 cells, with titers of $6.0 \log \mathrm{TCID}_{50} / \mathrm{mL}$ and $7.0 \operatorname{logLD} \mathrm{D}_{50} / 30 \mu \mathrm{L}$ (lethal dose by $50 \%)$ in BHK-21 and mice, respectively.

\section{SiRNAs}

The siRNAs described by Brandão et al. (2007) (Table 1), complementary to different regions of RABV N protein mRNA, were synthesized in a duplex format with two deoxi-timidines at the 3 ' end of each sense and anti-sense strands and resuspended as instructed by the manufacturers (Invitrogen, Carlsbad, CA, USA) and used for cell and mice trials.

\section{In vitro assays}

Each of the three siRNA was tested individually in the in vitro assays. Twenty four hour-old BHK-21 cells grown in 96 well-plates (one test and one control plate for each RNA, in duplicate) were inoculated with $200 \mu \mathrm{L}$ of 100 to $0.1 \mathrm{TCID}_{50}$ of PV in 10 -fold dilutions in serum-free minimal essential medium (MEM) from columns 1 to 10 and incubated at $37^{\circ} \mathrm{C} / 5 \% \mathrm{CO}_{2} / 2$ hours to allow viral penetration(Shankar and Koprowski, 1991), after this incubation period, virus dilutions were discarded and $200 \mu \mathrm{L}$ of serum-free MEM were added. Next, $100 \mu \mathrm{L}$ of 1:50 Lipofectamine 2000 (Invitrogen, Carlsbad, CA, USA) combined with $10 \mu \mathrm{M}$ of each siRNA in a $1: 1(\mathrm{v} / \mathrm{v})$ proportion, prepared according to manufacturer's instructions, were added from columns 1 to 10 . In columns 11 and $12,100 \mu \mathrm{L}$ of Lipofectamine 2000 and serum-free MEM (1:1 v/v) were added as a cytotoxicity control. Simultaneously, in the control plates, $100 \mu \mathrm{L}$ of Lipofectamine 2000 and serumfree MEM (1:1 v/v) were added from columns 1 to 10 and $100 \mu \mathrm{L}$ of serum-free MEM in columns 11 and 12 (cells control). The plates were incubated at $37{ }^{\circ} \mathrm{C} / 5 \% \mathrm{CO}_{2} / 22 \mathrm{~h}$ to a total 24-hour post-inoculation incubation with at least two RABV replication cycles (Shankar and Koprowski, 1991). Finally, the plates were tested by direct immunofluorescence assay (DFA) with anti-RABV nucleocapsid rabbit fluorescein isotiocianate conjugate (Bio-Rad $\left.{ }^{\mathrm{TM}}\right) \mathrm{ac}-$ cording to manufacturer's instructions and SpearmanKärber titters were calculated considering as positive wells with at least one fluorescent focus.

\section{In vivo experiment}

All In vivo assays in this investigation were conducted with 21 day-old albino-Swiss mice weighing 11 to $14 \mathrm{~g}$, kept at 21 to $25{ }^{\circ} \mathrm{C}$, water and food ad libitum and 12 hours with light/day; all animal trials were approved by the Bioethics Committee of the School of Veterinary Medicine, University of São Paulo, Brazil (protocol number 1357/2008). PV virus was diluted from 10.000 to $1 \mathrm{LD}_{50}$ in $30 \mu \mathrm{L}$, inoculated by the intracerebral route by the method described by Koprowski (Koprowski 1996) in 10 mice/ dose, divided in treated and control groups. Two hours after inoculation, the treated group was injected by the intracerebral route with $30 \mu \mathrm{L}$ of an equimolar pool of the three siRNAs combined with 1:1 (v/v) with Lipofectamine 2000, while the control group was mock-treated with $30 \mu \mathrm{L}$ of serum-free MEM/ Lipofectamine 2000 1:1 combination. Treated and control groups were observed daily during 30 days for rabies signals (seizures, ataxia, hyperesthesia, paralysis and death). The central nervous systems of the dead animals (including those euthanized after 30 days of observation) were tested by DFA as described above. Animals presenting both signals of rabies and a positive DFA result were considered as positives.

\section{Evaluation of Lipofetamine 2000 cytotoxicity in mice}

In order to evaluate the cytotoxicity of the transfect on reagent in vivo, five mice were injected intracranially with $30 \mu \mathrm{L}$ of Lipofectamina 2000 1:50/ serum-free MEM in an 1:1 (v/v) combination, while, five mice (control group) were injected with $30 \mu \mathrm{L}$ of only serum-free MEM and both groups were observed for 30 days for any clinical manifestations.

\section{Results}

\section{In vitro assays}

In the in vitro siRNA assay the higher drop in viral titter in the treated plates in comparison with the control

Table 1 - siRNAs used for post-transcriptional gene silencing of RABV nucleoprotein. Initial position relates to PV strain (GenBank accession number A14407.1)

\begin{tabular}{lllc}
\hline siRNA & Sequence & & Initial position \\
\hline RNA124 & sense & 5' GCCUGAGAUUAUCGUGGAG 3' & 123 \\
& anti-sense 5' & AUCCACGAUAAUCUCAGGC 3' & 749 \\
RNA750 & sense & 5' GCACAGUUGUCACUGCUUC 3' & \\
& antis-sense 5' & UAAGCAGUGACAACUGUGC 3' \\
RNAB & sense & 5' GACAGCUGUUCCUCACUCG 3' & 903 \\
& anti-sense 5' & AGAGUGAGGAACAGCUGUC 3' & \\
\hline
\end{tabular}


plates was found for the siRNAB treatment (Table 2), but siRNAs 124 and 750 caused drops in titters close to that found for siRNAB. For columns 11 and 12 of all treated and control plates, which were not inoculated with RABV and received the Lipofectamine 2000/ serum free MEM, no fluorescent focus was detected and no cytotoxyc effect was detected in the monolayers when compared to the control cells (which received only serum-free MEM).

\section{In vivo experiment}

In the group of mice inoculated with $100 \mathrm{LD}_{50}$ and treated with the pool of siRNAs, there was a survival rate of $30 \%$, while, in the control (mock-treated group) inoculated with the same dose, all animals died. With regard to the animals inoculated with $10 \mathrm{LD}_{50}$, the survival rate among the treated animals and mock-treated animals were $70 \%$ and $90 \%$, respectively. For the animals inoculated with $1 \mathrm{LD}_{50}$, both for the treated and control animals, the survival rate was $100 \%$ while, for the groups inoculated with 1,000 and $10,000 \mathrm{LD}_{50}$, mortality rates were $100 \%$ for both treated and control animals. All animals which died after the presentation of rabies tested positive for RABV antigens by the DFA, while all surviving animals (euthanized after 30 days of observation), tested negative.

\section{Evaluation of Lipofetamine 2000 cytotoxicity in mice}

All five animals injected intracranially with the Lipofectamine 2000/ serum-free MEM, as well as the other five injected by the same route with only serum-free MEM survived the 30-day observation period with no clinical manifestations or observable health problems.

\section{Discussion}

Observing the titers of the PV strain after the treatment of infected BHK-21 cells with the three different siRNAs, the drop in the titer ranged from 0.72 to $0.87 \mathrm{log}$, with a more intense effect observed for siRNAB. These results demonstrate that all three siRNAs used in this study are similarly efficient when used in separate or as pools, as described by Brandão et al. (2007).

When the three siRNAs were administered as a pool in equimolar concentrations via the intracranial route in mice previously inoculated with the PV strain, a dosedependent effect between the virus challenge dose and the

Table 2 - PV titers after treatment with the three different siRNAs in BHK-21 cells previously infected with the virus.

\begin{tabular}{lcc}
\hline Treatment & Titer $\left(\log \mathrm{TCID}_{50} / \mathrm{mL}\right)$ & $\begin{array}{c}\text { Titer difference regarding } \\
\text { the control }\end{array}$ \\
\hline siRNA 124 & 5.71 & 0.72 \\
siRNA B & 5.56 & 0.87 \\
siRNA 750 & 5.65 & 0.78 \\
Control & 6.43 & \\
\hline
\end{tabular}

survival rates was evident, resulting in $30 \%$ of survival in mice inoculated with $100 \mathrm{LD}_{50 \%}$, an indication that the treatment protocol used herein is effective in RABV infections with intermediate doses.

An inverse correlation exists between viral RNA synthesis by transcription and virulence as the accumulation of capsid-binding proteins makes the genomic RNA enclosed in an structure unable support further RNA synthesis (Dietzschold et al., 2008), i.e., the more mRNA for M or N proteins, for instance, the more these proteins are synthesized, encapsidating genomic RNA and making less RNA available for viral synthesis and leading thus to a lower virus titer. Thus, in the case of PV at $50 \mathrm{LD} 50_{50 \%}$ in the treated group, it might be speculated that the siRNAs have lowered N mRNA to a level in which RNP encapsidation is diminished and the now nude viral RNA is available to continued RNA synthesis and higher viral titers with a consequent higher virulence, explaining the apparently contradictory results for the higher survival rate of the untreated animals at the same viral dosis

Nonetheless, the influence of the siRNA initial doses must be taken into account, which, in the present study, was 1 and 0.3 nmols in BHK-21 cells and mice, respectively.

Higher doses might be required for a more effective antiviral effect, as shown by Kumar et al. (2006) who used $3.2 \mathrm{nmol}$ of a siRNA against West Nile virus transfected with a cationic lipid six hours after infection in mice and obtained a $100 \%$ survival rate. Still, a $200 \mathrm{nmol}$ amount of siRNA, with is 200 times higher than the amount used in BHK-21 cells in the present study, also resulted in an almost $100 \%$ survival rate in MK2 cells infected with Monkeypox virus (Alkhalil et al., 2009).

Regarding the Lipofectamine 2000 cytotoxicity assay, BHK-21 cells showed no microscopic alterations after 22 hours and, on the same way, mice injected with Lipofectamine 2000 by the intracranial route showed any signs of toxicity.

The efficiency of cationic lipids as siRNA transfecting agents by the intracranial route in mice, as used in the present study, has been previously described for the Chandipura letal encephalitis virus (Kumar and Arankalle, 2010), showing that this strategy is validated against neurotropic viruses.

The use of plasmid-delivered pre-micro RNAs transfected with Lipofectamine 2000 also targeted to RABV nucleoprotein mRNA in N2A (mice neuroblastoma) cells was also found efficient to decrease the level of RABV genomic RNA against the CVS strain (Israsena et al., 2009), demonstrating that RABV intracellular cycle can be efficiently inhibited.

However, improved delivery systems are paramount for efficient gene silencing and increases in the time of action and concentration of siRNAs in the cytoplasm can be achieved with plasmids or viral vectors of gene silencing (Aigner 2006). 
A further improvement of the delivery of siRNAs to the central nervous system is the conjugation of siRNAs with neurotropic proteins, as reported by Kumar et al. (2007) after the use of a chimeric RABV glycoprotein conjugated with siRNAs against the neurotropic Japanese encephalitis virus, showing a transfection efficiency similar to that obtained with Lipofectamine 2000 when tested in mice and in N2A cells.

In summary, the study presented herein on the use of RNAi against rabies show that this valid antiviral strategy for higher rates of success in rabies treatment protocols in the future.

\section{Ethical approval}

All animal trials were approved by the Bioethics Committee of the School of Veterinary Medicine, University of São Paulo, Brazil (protocol number 1357/2008).

\section{Acknowledgments}

The authors are grateful to FAPESP (Fundação de Amparo à Pesquisa do Estado de São Paulo), Grant \# 2008/51519-8, for the financial support.

\section{References}

Acha PN, Szyfres B (2003) Zoonosis y Enfermidades Comunes Transmisibles al Hombre y a los Animales. Pan American Health Organisation, Washington, p. 580 (Série Publicación Científica y Técnica).

Aigner A (2006) Delivery Systems for the direct application of siRNAs to induce RNA interference (RNAi) in vivo. J Biomed Biotechnol 4:1-15.

Alkhalil A, Strand S, Mucker E, Huggins JW, Ahrling PB, Ibrahim SM (2009) Inhibition of Monkeypox virus replication by RNA interference. J Virology 6:1-14.

Brandão PE, Castilho JG, Fahl W, Carnieli Jr P, Oliveira NR, Macedo CI, Carrieri ML, Kotait I (2007) Short-interfering RNAs as antivirals against rabies. Braz J Infect Dis 11:224225.
Butron EC, Burns DK, Opatowsky MJ, El-Feky WH, Fischbach B, Melton L, Sanchez E, Randall H, Watkins DL, Chang J, Klintmalm G (2005) Rabies encephalomyelitis: Clinical, neuroradiological, and pathological findings in 4 transplant recipients. Arch Neurol 62:873-882.

Dietzschold B, Li J, Faber M, Schnell M (2008) Concepts in the pathogenesis of rabies. Future Virol 3:481-490.

Israsena N, Supavonwong P, Ratanasetyuth N, Khawplod P, Hemachudha $T$ (2009) Inhibition of rabies virus replication by multiple artificial microRNAs. Antiviral Res 84:76-83.

Kaplan MM (1996) Safety precautions in handling rabies virus. In: Koprovsky H (ed) The Laboratory Technicies in Rabies. WHO, Geneva, pp 130-133.

Koprowski H (1996)The mous inoculation test. In: Koprowski H (ed) The Laboratory Technicies in Rabies. WHO, Geneva, pp 45-46.

Kumar S, Arankalle VA (2010) Intracranial administration of P gene siRNA protects mice from lethal chandipura virus encephalitis. PloS One 5:1-5.

Kumar P, Wu H, McBride JL, Jung KE, Kim MH, Davidson BL, Lee SK, Shankar P, Manjunath N (2007) Transvascular delivery of small interfering RNA to the central nervous system. Nature 448:39-43.

Kumar P, Lee SK, Shankar P, Manjunath NA (2006) Single siRNA suppresses fatal encephalitis induced by two different flaviviruses. PLoS Med 3:0507.

Rupprecht CE, Honlon CA, Hemachudha T (2002) Rabies reexamined. Lancet Infect Dis 2:327-343.

Shankar VDB, Koprowski H (1991) Direct entry of rabies virus into the central nervous system without prior local replication. J Virol 65:2736-2738.

Tordo N, Poch O (1998) Structure of rabies virus. In: Campbell JB, Charlton KM (eds) Rabies. Kluwer Academic Publishers, London, pp 26-28.

Willoughby Jr RE, Tieves KS, Hoffman GM, Ghanayem NS, Lefond CMA, Schwabe MJ, Chusid MJ, Rupprecht CE (2005) Survival after treatment of rabies with induction of coma. N Engl J Med 352:2508-2514.

Wunner WH (1991) The chemical composition and molecular structure of rabies viruses. In: Baer GM (ed) The Natural History of Rabies. CRC Press, Boca Raton, pp 31-35.

All the content of the journal, except where otherwise noted, is licensed under a Creative Commons License CC BY-NC. 